\title{
Measurement of air drag as physics experiment enrichment at senior high school laboratory using the air track apparatus
}

\author{
Prasetyo Listiaji ${ }^{*}$, Muhamad Taufiq ${ }^{2}$, Ni Luh Tirtasari ${ }^{3}$, Anisia Kholidah ${ }^{4}$, Nia Annisa Ferani \\ Tanjung 5 \\ 1,2.3,4 Departement of Integrated Sciences, Faculty of Mathematics and Sciences, Universitas Negeri Semarang \\ ${ }^{5}$ Software Engineering, Faculty of Informatics, Institute Teknologi Telkom Purwokerto
}

*Corresponding Address: p.listiaji@mail.unnes.ac.id

\begin{tabular}{|c|c|}
\hline Art & \multirow{11}{*}{$\begin{array}{l}\text { ABSTRACT } \\
\text { Linear air track is often used in physics learning for linear motion experiments } \\
\text { because it can reduce friction between objects with trajectories. However, the } \\
\text { use of air tracks for motion experiments in schools often does not care about } \\
\text { aspects of air drag, so the purpose of this study is to calculate the air friction } \\
\text { contained in the air track and as an offer of enrichment experiments at senior } \\
\text { high school. The research method used is an experimental method that uses a } \\
\text { set of air track experimental devices consisting of trajectors, carts, blower, } \\
\text { and time counters with light sensors. Cart objects with a mass of } 120.02 \text { gram } \\
\text { is given the initial velocity variation } 12.272 \mathrm{~cm} / \mathrm{s}, 16.286 \mathrm{~cm} / \mathrm{s} \text { and } 24.599 \\
\mathrm{~cm} / \mathrm{s} \text {. Then the time recorded when the cart crosses the distance of } 10 \mathrm{~cm} \text { to } \\
110 \mathrm{~cm} \text { at intervals of } 10 \mathrm{~cm} \text {. This experiment is conducted in the Integrated } \\
\text { Science Laboratory, Faculty of Mathematics and Natural Sciences, } \\
\text { Universitas Negeri Semarang. The second Newton law has been derived to } \\
\text { obtain a special exponential function, so the relation between distance and } \\
\text { time is obtained. The non-linear relation between distance and time shows the } \\
\text { effect of air drag. Then, fitting the graph of the distance and time relation so } \\
\text { that the air drag constants obtained are }(10.6 \pm 0.1) \text { gram } / \mathrm{s},(10.6 \pm 0.2) \\
\text { gram/s, and }(11.1 \pm 0.2) \text { gram/s. The results of the air drag constants obtained } \\
\text { can be additional data as a factor affecting experiments using linear air track } \\
\text { and can be enrichment experiments at senior high school laboratory. }\end{array}$} \\
\hline Artic & \\
\hline Rece & \\
\hline & \\
\hline April 30th 2020 & \\
\hline & \\
\hline & \\
\hline & \\
\hline $\mathrm{Sc}$ & \\
\hline & \\
\hline catio & \\
\hline
\end{tabular}

() 2020 Physics Education Department, UIN Raden Intan Lampung, Indonesia.

\section{INTRODUCTION}

In the beginning, the experimental motion of objects in schools often used a ticker timer, but there were many obstacles (Prima et al., 2016; Marinho \& Paulucci, 2016), so now physics experiments using linear air track apparatus have been widely offered for physics learning in school laboratories. Students can easily carry out dynamics and kinematics experiments using air tracks because the position, speed, and acceleration of objects can be easily measured and observed. After all, it is assisted by a photo gate-based time counter device (Saphet et al.,
2002). There is another technology to observe the motion of objects. It is a video tracker (Yusuf, 2016), but the video tracker is less practical because it has to process image data first.

Mechanical experiments without using the air track should also consider friction between objects with trajectory (Minkin, \& Sikes, 2017). One of the advantages of air track is that the system is considered ideal because friction is very small (considered non-existent) due to air exhaled between objects and trajectories. But actually, this system is not ideal because there is still air 
drag that affects it. In advanced experiments can be introduced to students about the effects of air drag in motion. In this study, we will measure the air drag produced by the air track apparatus system in a linear motion experiment.

Several studies using air track apparatus have been carried out including experiment of harmonic oscillator damped (Hauko et al., 2018; Hinrichsen \& Larnder, 2018; Hinrichsen, 2018), one dimension collision of two objects experiment (Saphet et al., 2017), Investigation of magnetic damping (Oyelade, 2019). Also, some of the classical mechanical studies experiments have been concern the effects of air drag including modeling the effects of the air intake on PingPong ball motion (Thuecks \& Demas, 2019), cart experiments on an inclined plane (Amato \& Williams, 2010), projectile motion experiments (Blanco, 2018; Mohazzabi, 2018), research of aerodynamics in the classroom and ballpark (Cross, 2012), freefall motion experiment (Mohazzabi, 2011), juggling a spinning Ping-Pong ball experiment (Widenhorn, 2016), Teaching kinematic graphs in an undergraduate course (Vaara \& Sasaki, 2019), coupled oscillators (Case et al., 2017), research on how mechanical energy vanish into thin air (Moreno, 2018), Measuring the coefficient of restitution (González et al, 2017),

Previously, a study to measure air drag in air track apparatus used the concept of an inclined plane, so that gravity force which is parallel to the track affects the motion of objects (Mungan, 2012). This requires that we look for the value of gravity acceleration first. In this study, only using a simple linear motion system where objects are given a certain initial speed so that it is easier to experiment. The time counter in this experiment uses sensitive light sensors that are directly connected to a computer also makes it easy for us to record the time when objects cross certain distances that we have set. Also, the study of two objects collisions using air track apparatus ignores the role of air drag (Saphet et al., 2017). So that study on measuring air drag in air tracks apparatus is very important to do because information about air drag can be an improvement in physics experiments in school. The Effect of water drag is also used in free-fall motion experiments (Sibert et al., 2019), and projectile motion experiments (Azhikannickal, 2019)

From the literature study above, the advantage of this research is that the measurement of air drag only uses the straight-motion experimental method, so that it will be simpler if it is done by students than the measurement of air resistance by other studies such as Mungan (2012), which uses the inclined plane of the experiment. This experiment also uses a time counter with a sensitive light sensor and is directly related to the computer so that data processing is faster. This study also corrected previous research in the use of air tracks that ignored air drag factors.

\section{METHODS}

\section{Theoretical Explanation}

The easiest explanation of motion is to use Newton's Law. Newton's first law explains the inertia of an object (Halliday et al., 2010). If an object initially has velocity $v$, then the speed will be constant when there is no force acting on the object. Suppose that in a laboratory experiment, the cart moves linearly with a low velocity on the air track. The cart will get an air drag force so that velocity will decrease over time. For low velocity, the air drag force $F_{\text {air }}$ is proportional to velocity $v$ (equation 1 ) (Merci, 2016).

$$
F_{\text {air }}=-c v
$$

where $c$ is air drag constant, which depends on the dimension of an object and air density. Then, equation 2 explains this cart motion based on the second Newton's Law.

$$
\begin{aligned}
& -c v=m \frac{d v}{d t} \\
& \frac{-c}{m} d t=\frac{1}{v} d v
\end{aligned}
$$

We have the deferential equation of second Newton's Law (equation 3), then its equation is integrated (time $\mathrm{t}$ is integrated from $t_{0}=0$ until $t$, and $v$ is integrated form $v_{\mathrm{o}}$ 
until $v$ ) so that the relation of velocity and time can be obtained as equation 4 .

$$
v=v_{0}\left(e^{-\frac{c}{m} t}\right)
$$

Equation 4 shows that velocity is not constant, but it will decrease over time. We know that velocity $v(t)$ is the first derivation of position $s(t)$, so the integration result from equation 4 , will be expressed in equation 5 ,

$$
s=\frac{m}{c} v_{o}\left(1-e^{-\frac{c}{m} t}\right)
$$

\section{Place and Time of Research}

This research was conducted in the Integrated Science Laboratory, Faculty of Mathematics and Natural Sciences, Universitas Negeri Semarang, from July to November 2019. The diagram of the experiment is shown in Figure 1.

\section{Materials and Apparatus}

Experiments used 1 set of air tracks apparatus consisting of $1.5 \mathrm{~m}$ trajectories, the cart with a mass of 120.02 grams, and a blower to drain air on the trajectories, a light sensor-based time counter. The schematic series of devices can be seen in Figure 1.

\section{Experiment Procedure}

The diagram of the experiment is shown in Figure 2. At first, the cart was moving at a certain velocity. The initial speed was measured based on the time counter readable results when the cart position $s=0$. In this study the three initial velocity variations used are $12.272 \mathrm{~cm} / \mathrm{s}, 16.286 \mathrm{~cm} / \mathrm{s}$ and 24.599 $\mathrm{cm} / \mathrm{s}$. The cart moved along the air track with the hypothesis the velocity decreased with time due to the air drag force. The sensor read the cart movements while crossing the air track. Sensors were installed for distances of 10.0 to $110.0 \mathrm{~cm}$ at intervals of $10.0 \mathrm{~cm}$ so that we can record 11 times.

Because this experiment uses a sensitive light sensor, the external factor that influences is the ambient light which can influence the reading of the compilation time of the object passing through the path. However, this has been anticipated that the distance is as close as possible between the sensor and the part of the object that is read by the sensor so that the ambient light that enters the sensor will be reduced.

\section{Data Analysis}

Time and distance data were then tabulated and graphed. The graphs obtained were then fitted with special exponential functions (Equations 6), which correspond to equation 5. The $y$-axis is the distance $(s)$ while the $x$-axis is time $(t)$.

$$
y=a\left(1-e^{-b t}\right)
$$

where $a=\frac{m}{c} v_{o}$ dan $b=\frac{c}{m}$

We used the Origin Lab software for fittings. After graph fitting, we analyzed the graph to find the values of $a$ and $b$ so we can calculate the value of $c$ as the constant of air drag. After we got the value of the air drag coefficient, we plotted the relation graph between velocity and time according to equation (4).

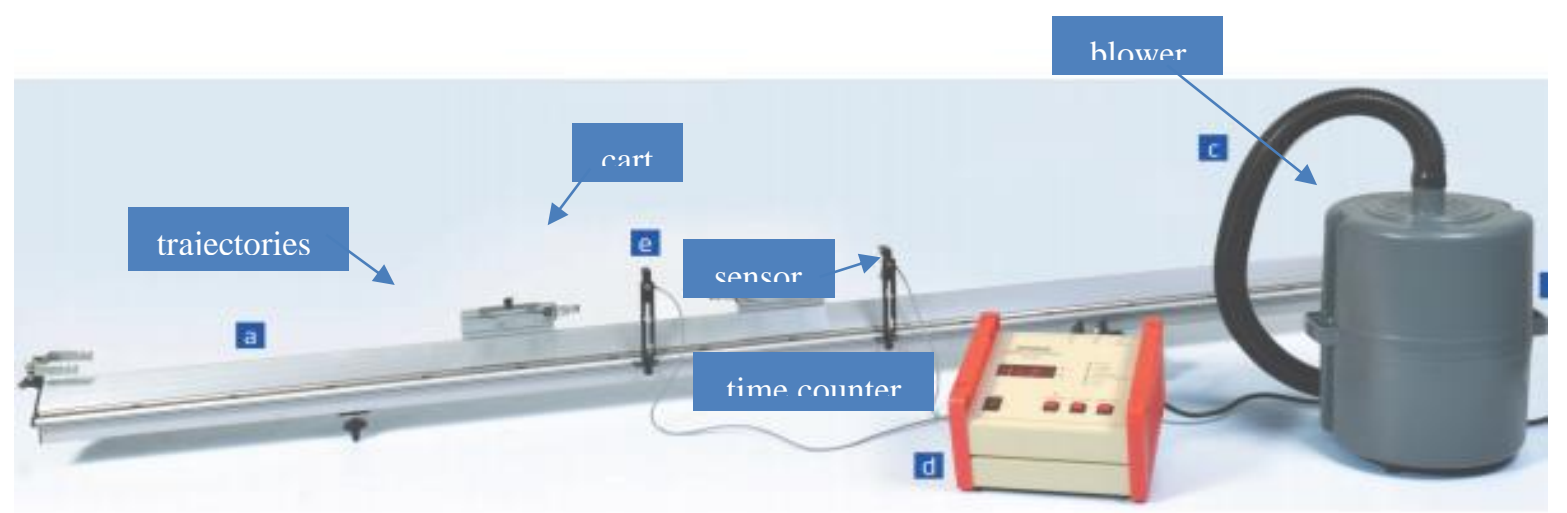

Figure 1. Air track apparatus Set-up 


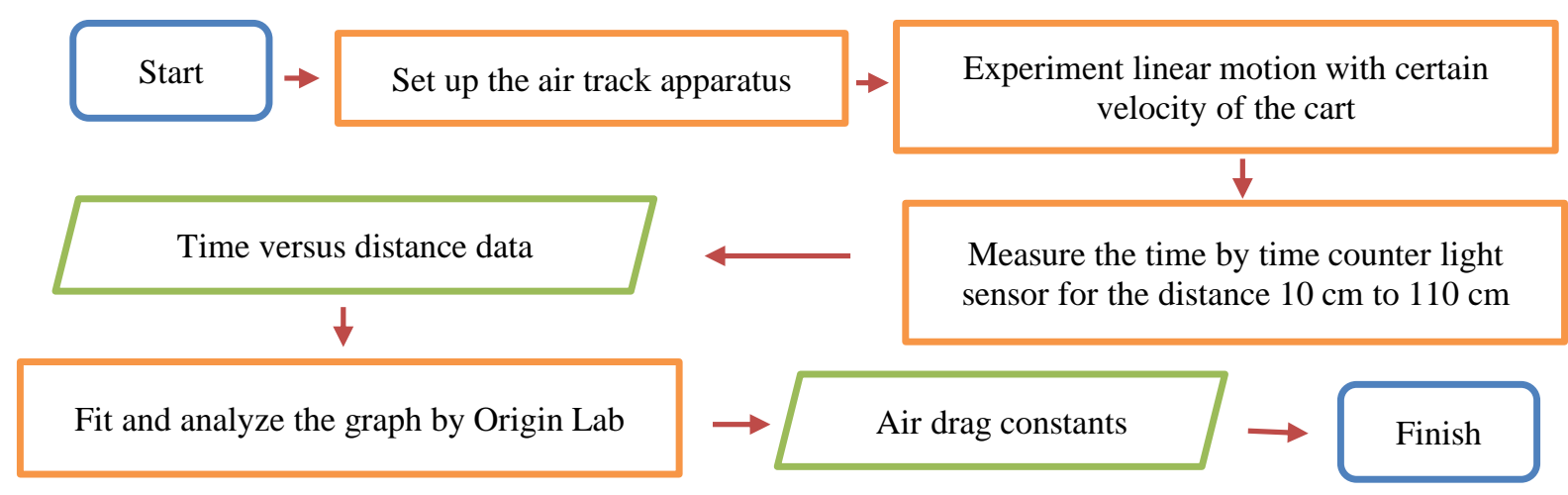

Figure 2. Diagram of The Experiment

\section{RESULTS AND DISCUSSION}

The experimental results show that there is a non-linear relationship between distance and time. If plotted into a graph (Figure 3), then according to equation 6.

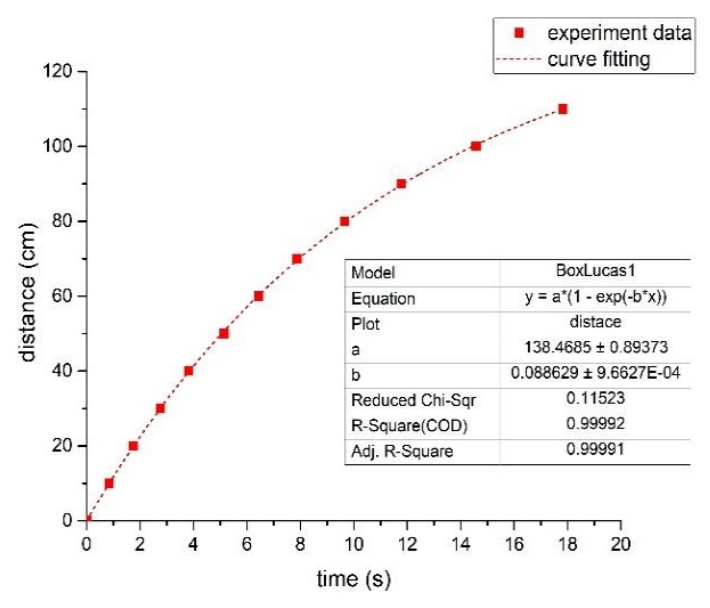

(a)

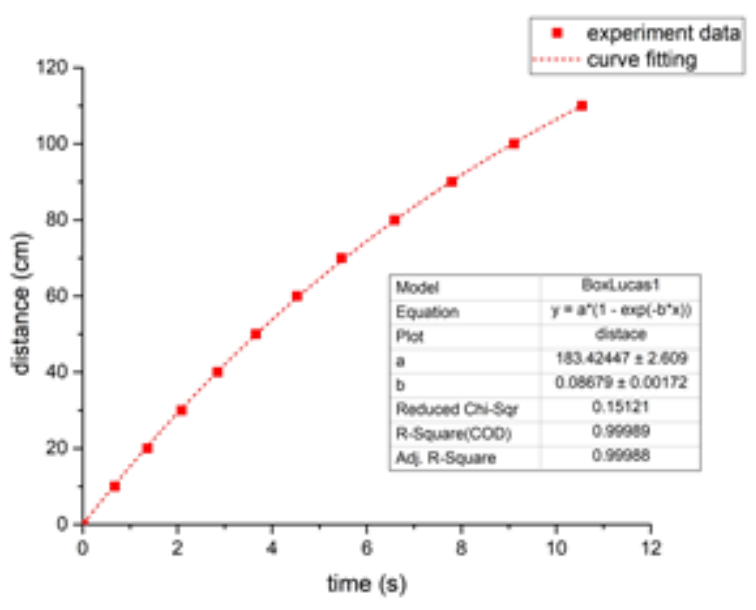

(b)

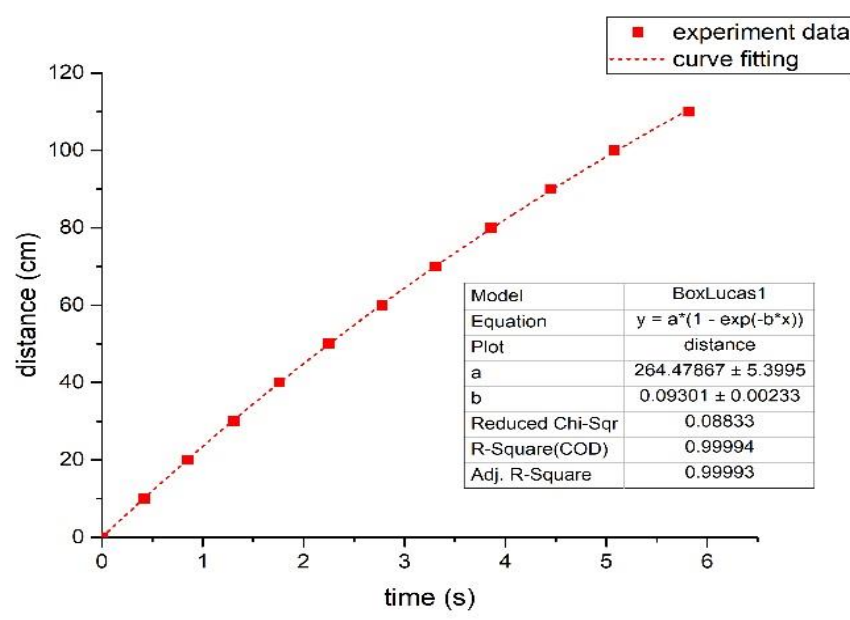

(c)

Figure 3. Graph plot of distance versus time. (a) for $v_{0}=12.272 \mathrm{~cm} / \mathrm{s}$; (b) for $v_{0}=16.286 \mathrm{~cm} / \mathrm{s}$; (c) for $v_{0}=24.599 \mathrm{~cm} / \mathrm{s}$ 
Graphs that are not linear in Figure 3 show that cart motion is not a regular linear motion at a constant velocity. If the velocity is constant, then a linear distance versus time graph will be generated. The pattern shown by the experimental results indicates that there are effects of air drag. These results provide corrections to the study conducted by (Hauko et al., 2018; Hinrichsen \& Larnder, 2018; Hinrichsen, 2018; Saphet et al., 2017; Oyelade, 2019) who in his experiment ignored air drag.

Through graph analysis, the values of $a$ and $b$ have been obtained so that the air drag constants can be calculated. The calculation results are shown in Table 1.

If seen for the initial velocity of 12.272 $\mathrm{cm} / \mathrm{s}$ and $16.286 \mathrm{~cm} / \mathrm{s}$, we get the same air drag constant, but there is a difference with the results of the air drag constant for the initial velocity of $24.599 \mathrm{~cm} / \mathrm{s}$. This phenomenon occurs because, for higher velocity, the air drag force is no longer proportional to the object velocity but is proportional to the square of object velocity $F_{\text {air }}=-c v^{2} \quad$ (Blanco, 2018; Mohazzabi, 2018; Cross, 2012). These results provide corrections to the study (Merci, 2016) that equation 1 is not always appropriate for motion experiments.

The results of the air drag constants that have been obtained are then used to plot the graph of the velocity versus time (Figure 4).
We set a time scale interval from 0 seconds until 10 seconds. Figure 4 shows that the cart velocity decreases exponentially over time, according to equation 4 . This phenomenon indicates that the cart does not move at a constant velocity. The effect of air drag causes a decrease in velocity. These results are consistent with research conducted by Cross (2012), Hackborn (2016), and Li et al. (2016) that the effect of air drag causes the object velocity is not constant (decrease).

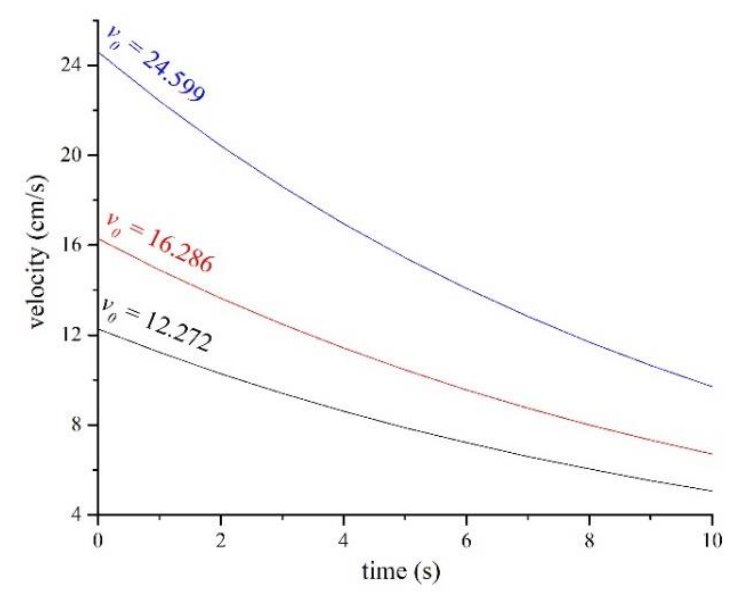

Figure 4. Graph plot of velocity versus time

The existence of air drags when using air track apparatus shows that experiments at school can be more advanced by considering air drag. The results of the air drag constant can be used as a correction factor in subsequent motion experiments.

Table 1. Calculation results of drag air constants with variations in initial velocity

\begin{tabular}{ccc}
\hline $\begin{array}{c}\text { Initial Velocity } v_{o} \\
(\mathrm{~cm} / \mathrm{s})\end{array}$ & $a$ & $\begin{array}{c}\text { Air Drag Constants } c \\
(\mathrm{gram} / \mathrm{s})\end{array}$ \\
\hline 12.272 & $138.5 \pm 0.9$ & $10.6 \pm 0.1$ \\
16.286 & $183.4 \pm 2.6$ & $10.6 \pm 0.2$ \\
24.599 & $284.5 \pm 2.4$ & $11.1 \pm 0.2$ \\
\hline
\end{tabular}

\section{CONCLUSION AND SUGGESTION}

Experiments of linear motion using the air track apparatus turned out not really without friction. The results showed that there was an effect of air drag that affected cart motion. The cart velocity has gradually decreased exponentially. The relation of distance versus time shows a trend that is not linear. Through the approach that the air drag force is proportional to the cart velocity, we got the results that the air resistance constant value is $(10.6 \pm 0.1) \mathrm{gram} / \mathrm{s}$ for the initial velocity of $12.272 \mathrm{~cm} / \mathrm{s}, \quad(10.6 \pm 0.2) \mathrm{gram} / \mathrm{s}$ for the initial velocity of $16.286 \mathrm{~cm} / \mathrm{s}$, and $(11.1 \pm$ 
0.2) $\mathrm{gram} / \mathrm{s}$ for the initial speed of 24.599 $\mathrm{cm} / \mathrm{s}$.

The results of the air drag constants obtained can be additional data, and senior high school laboratories as a factor affecting experiments using linear air track, and this experiment can be an enrichment physics experiment at senior high school laboratory. It would be better if the next experiment on measuring air drag could be a model offered in teaching enrichment of Newtonian mechanics experiments.

The research can be continued to lead to the validation of experimental results by asking students to repeat similar experiments but with different techniques such as mechanical energy or momentum approaches. Research can also lead to the study of students' misconceptions about the concept of air drag.

\section{AUTHOR CONTRIBUTIONS}

PL conceptualization and reviewing literature pertaining to the study. MT and AK prepared research design, writing finding and discussion, revision of manuscript. NL and MT collected data and analysis data. NA design and revision of manuscript.

\section{REFERENCES}

Amato, J. C., \& Williams, R. E. (2010). Turning a Common Lab Exercise into a Challenging Lab Experiment: Revisiting the Carton an Inclined Track. The Physics Teacher, 48(5), 322-323. https://doi.org/10.1119/1.3393065

Azhikannickal, E. (2019). Sports, smartphones, and simulation as an engaging method to teach projectile motion incorporating air resistance. The Physics Teacher, 57(5), 308-311. https://doi.org/10.1119/1.5098919

Blanco, P. (2018). Air drag in the projectile lab. The Physics Teacher, 56(5), 276276. https://doi.org/10.1119/1.5033863

Case, W. B., Tjossem, P. J., Abrams, K. G., \& St. Germaine-Fuller, J. F. (2017). Coupled oscillators driven with difference-frequency parametric position feedback. Journal of Applied Physics, 122(12), 124905.

https://doi.org/10.1063/1.4991887

Cross, R. (2012). Aerodynamics in the classroom and at the ball park. American Journal of Physics, 80(4), 289-297. https://doi.org/10.1119/1.3680609

González, M. Á., González, M. Á., Vegas, J., \& Llamas, C. (2017). Measuring the coefficient of restitution and more: A simple experiment to promote students' critical thinking and autonomous work. Physics Education, 52(5), 055002. https://doi.org/10.1088/13616552/aa71ea

Halliday, D., Resnick, R., \& Walker, J. (2010). Fundamentals of Physics Extended 9th Edition. In Wiley; 9 edition (November 16, 2010). John Wiley \& Sons.

Hauko, R., Andreevski, D., Paul, D., Šterk, M., \& Repnik, R. (2018). The teaching of the harmonic oscillator damped by a constant force: The use of analogy and experiments. American Journal of Physics, 86(9), 657-662.

https://doi.org/10.1119/1.5044654

Hackborn, W. W. (2016). On motion in a resisting medium: A historical perspective. American Journal of Physics, 84(2), 127-134. https://doi.org/10.1119/1.4935896

Hinrichsen, P. F. (2018). Coefficient of kinematic friction from damped oscillatory motion. Physics Education, 53(6), 065010 https://doi.org/10.1088/13616552/aadb28

Hinrichsen, P. F., \& Larnder, C. I. (2018). Combined viscous and dry friction damping of oscillatory motion. American Journal of Physics, 86(8), 577-584.

https://doi.org/10.1119/1.5034345

Li, A., Ma, L., Keene, D., Klingel, J., Payne, M., \& Wang, X. J. (2016). Forced oscillations with linear and nonlinear damping. American Journal of Physics, 
84(1), 32-37.

https://doi.org/10.1119/1.4935358

Marinho, F., \& Paulucci, L. (2016).

Kinematic measurements using an

infrared sensor. European Journal of

Physics, 37(2), 025003.

https://doi.org/10.1088/0143-

0807/37/2/025003

Merci, B. (2016). Introduction to Fluid Mechanics. In SFPE Handbook of Fire Protection Engineering (pp. 1-24). https://doi.org/10.1007/978-1-49392565-0_1

Minkin, L., \& Sikes, D. (2017). Measuring the coefficients of kinetic and rolling friction by exploring decaying massspring oscillations. Physics Education, 53(1), 015001.

https://doi.org/10.1088/13616552/aa8a55

Mohazzabi, P. (2011). When Does Air Resistance Become Significant in Free Fall? The Physics Teacher, 49(2), 8990. https://doi.org/10.1119/1.3543580

Mohazzabi, P. (2018). When Does Air Resistance Become Significant in Projectile Motion? The Physics Teacher, 56(3), 168-169. https://doi.org/10.1119/1.5025298

Moreno, J. (2018). Can mechanical energy vanish into thin air? American Journal of Physics, 86(3), 220-224. https://doi.org/10.1119/1.5019022

Mungan, C. E. (2012). Rolling friction on a wheeled laboratory cart. Physics Education, 47(3), 288.

https://doi.org/10.1088/00319120/47/3/288

Oyelade, A. O. (2020). Experiment study on nonlinear oscillator containing magnetic spring with negative stiffness. International Journal of Non-Linear Mechanics, 120, 103396.

https://doi.org/10.1016/j.ijnonlinmec.2019.1 03396

Prima, E. C., Mawaddah, M., Winarno, N., \& Sriwulan, W. (2016, February).
Kinematics investigations of cylinders rolling down a ramp using tracker. In AIP Conference Proceedings (Vol. 1708, No. 1, p. 070010). AIP Publishing LLC.

https://doi.org/10.1063/1.4941183

Saphet, P., Tong-On, A., \& Thepnurat, M. (2017). One dimensional two-body collisions experiment based on LabVIEW interface with Arduino. Journal of Physics: Conference Series, 901(1), 012115. https://doi.org/10.1088/17426596/901/1/012115

Siebert, C., DeStefano, P. R., \& Widenhorn, R. (2019). Comparative modeling of free fall and drag-enhanced motion in the classical physics drop experiment. European Journal of Physics, 40(4), 045004.

https://doi.org/10.1088/13616404/ab1fbc

Thuecks, D. J., \& Demas, H. A. (2019). Modeling the effect of air-intake aperture size in the ping-pong ball cannon. American Journal of Physics, $87(2)$, 136-140. https://doi.org/10.1119/1.5086614

Vaara, R. L., \& Sasaki, D. G. G. (2019). Teaching kinematic graphs in an undergraduate course using an active methodology mediated by video analysis. LUMAT: International Journal on Math, Science and Technology Education, 7(1), 1-26. https://doi.org/10.31129/LUMAT.7.1.3 74

Widenhorn, R. (2016). The physics of juggling a spinning ping-pong ball. American Journal of Physics, 84(12), 936-942.

https://doi.org/10.1119/1.4964104

Yusuf, E. (2016). Using Tracker to Engage Students' Learning and Research in Physics. Pertanika Journal Science and Technology, 24(2), 483-491. 